\title{
Competências para atuação em vigilância sanitária: abordagem metodológica
}

\section{Competencies for acting in health surveillance: methodological approach}

\section{Cláudia Maria da Silva Marques',* (iD}

Claudia Passos Guimarães Rabelo" (iD
Núcleo de Estudos de Saúde Pública (NESP), Centro de Estudos Avançados Multidisciplinares (Ceam), Universidade de Brasília (UnB), Brasília, DF, Brasil

" Agência Nacional de Vigilância Sanitária (Anvisa), Brasília, DF, Brasil

\footnotetext{
* E-mail: claudiamariamarques@ gmail.com
}

\begin{abstract}
RESUMO
Introdução: A adoção do modelo de competências no mundo do trabalho está relacionada ao uso, ao controle, à formação e à avaliação do desempenho da força de trabalho, o que, a partir da Lei de Diretrizes e Bases da Educação Nacional (LDB), reorientou a prática pedagógica organizada em disciplinas para uma prática voltada para a construção de competências. Na saúde, o novo referencial da educação tem sido alinhado às demandas das práticas profissionais, à concepção de saúde definida pelo Sistema Único de Saúde (SUS) e à qualidade requerida nas ações de saúde prestadas aos indivíduos e à sociedade, que incluem os cuidados sob responsabilidade da vigilância sanitária. Objetivo: Apresentar a abordagem metodológica utilizada para elaborar o referencial de competências profissionais específicas para atuação em vigilância sanitária e apontar possibilidades de aplicação do material produzido. Método: 0 método utilizado é constituído por seis etapas: as quatro primeiras etapas realizadas por meio de análise documental; a quinta etapa por meio de cinco oficinas de trabalho; e a sexta etapa, validação. Resultados: Foi apontado um conjunto de sete competências profissionais específicas para atuação nas áreas da vigilância sanitária definidas para a proposta do referencial. Foram identificados, para cada competência, as ações e os saberes que devem ser desenvolvidos pelos profissionais. Conclusões: A metodologia possibilitou maior visibilidade das práticas desenvolvidas pelos profissionais da vigilância sanitária, a conformação de um referencial de competências sintonizado com a missão da vigilância sanitária, estratégias e macroescolhas, valores e princípios levantados como transversais às competências. 0 referencial de competências apresentado alinha-se às do perfil de competência do gestor da vigilância sanitária e, após validado, subsidiará a organização de programas de educação permanente e continuada para os profissionais.
\end{abstract}

PALAVRAS-CHAVE: Competências Específicas; Vigilância Sanitária; Educação Permanente

\section{ABSTRACT}

Introduction: The adoption of the skills model in the world of work is related to the use, control, training and evaluation of the performance of the workforce, which, based on the the Law of Guidelines and Bases of National Education, redirected the pedagogical practice organized in disciplines towards a practice aimed at building skills. In health, the new educational framework has been aligned with the demands of professional practices, the concept of health defined by the Unified Health System and the quality required in health actions provided to individuals and society, which include care under the responsibility of surveillance sanitary. Objective: To present the methodological approach used to elaborate the referential of specific professional competences to act in health surveillance and to point out possibilities of application of the produced material. Method: The method used consists of six stages: the first four stages performed by means of documentary analysis; fifth stage through five workshops; sixth step, validation. Results: A set of seven specific professional competences was pointed out to work in the areas of health surveillance defined for the proposal of the referential. For each competency, the 
actions and knowledge that should be developed by professionals were identified. Conclusions: The methodology allowed for greater visibility of the practices developed by health surveillance professionals, the creation of a competence framework in line with the mission of health surveillance, strategies and macro choices, values and principles raised as transversal to the competencies. The competence reference presented is in line with the competence profile of the health surveillance manager and, after validation, will subsidize the organization of permanent and continuing education programs for professionals.

KEYWORDS: Specific Skills; Health Surveillance; Permanent Education

\section{INTRODUÇÃO}

Os temas relacionados ao modelo das competências vêm sendo estudados e debatidos por vários autores e em vários fóruns, tanto na perspectiva da educação como na do trabalho.

Segundo a Organização Internacional do Trabalho' ${ }^{1}$ (OIT), o conceito de competência profissional surgiu nos anos 1960 nos Estados Unidos (EUA), podendo-se acrescentar que o conceito de formação e qualificação baseadas em competências surgiu nos EUA nos anos 1960 e na Inglaterra nos anos 1980. A OIT ${ }^{1}$ assinala ainda que, cada país, segundo seu estágio de desenvolvimento, foi criando seu modelo de competência e, consequentemente, adotando conceitos pertinentes a esse modelo.

No mesmo documento, a OIT afirmava que os países que mais acentuavam a importância do modelo de competência profissional eram Alemanha, Austrália, Canadá, Espanha, EUA, México e Reino Unido, sendo que, em cada um deles, havia diferentes conotações sobre o conceito de competência e sua forma de classificação. Nesse sentido, no Brasil, como em outros países, não existe um conceito único de competência.

Deluiz ${ }^{2}$ considerou que a discussão sobre o modelo de competências começou no mundo empresarial a partir dos anos 1980, em um contexto de crise estrutural do capitalismo nos países centrais, que começou a se configurar no início da década de 1970. Assim, a adoção do modelo de competências no mundo do trabalho está relacionada ao uso, ao controle, à formação e à avaliação do desempenho da força de trabalho diante das novas exigências relacionadas ao padrão de acumulação capitalista: competitividade, produtividade, racionalização de custos, entre outros.

Por outro lado, segundo essa mesma autora ${ }^{2}$, a discussão sobre o enfoque das competências chega ao mundo da educação a partir dos questionamentos feitos ao sistema educacional diante das exigências do sistema produtivo. A autora ressalta, no entanto, que a noção de competência é "fortemente polissêmica, tanto no mundo do trabalho quanto na esfera da educação" e que essa polissemia decorre de "diferentes visões teóricas, sustentadas em matrizes epistemológicas diversas”.

Assim, segundo Deluiz ${ }^{3}$, a noção de competência é uma construção social, alvo de disputas políticas em torno do seu significado, o que reforça a percepção de que as competências variam historicamente de acordo com contextos sociais, econômicos e culturais, e dependem dos embates entre as visões de mundo dos diversos atores sociais.
No Brasil, em 1996, foi iniciado legalmente o processo de reforma da educação, com a aprovação da Lei n ${ }^{\circ} 9.394$, de 20 de dezembro de 1996 - Lei de Diretrizes e Bases da Educação Nacional (LDB) ${ }^{4}$. Para Ramos ${ }^{5}$, a partir da LDB, as reformas curriculares passaram a reorientar a prática pedagógica organizada em disciplinas para uma prática voltada para a construção de competências.

Para o setor saúde, essa proposição tornou emergente a necessidade de aprofundar o estudo acerca desse novo referencial estruturante da educação frente às necessidades de uma formação ampliada, condizente com as demandas das práticas profissionais, com a concepção de saúde definida pelo Sistema Único de Saúde (SUS) e com a qualidade requerida às ações de saúde prestadas aos indivíduos e à sociedade ${ }^{6}$, em que se incluem os cuidados sanitários sob responsabilidade da vigilância sanitária.

Por isso, a noção de competência como estruturante da formação profissional e da educação permanente dos trabalhadores do SUS não se restringe à dimensão técnico-instrumental; ela deve contribuir para a renovação do próprio processo de formação, valorizando e promovendo a autonomia e a emancipação dos trabalhadores e das relações de trabalho².

Compreendendo a competência como condicionada pelos contextos econômico, social e político, admite-se que seu desenvolvimento não se restringe à perspectiva individual, uma vez que ela é construída ao longo da vida profissional, que pressupõe compartilhamento de experiências e práticas coletivas, em contextos que sempre variam². A competência é, nesse sentido, evolutiva e interativa.

O Ministério da Saúde ${ }^{6}$ apontou que a competência profissional em saúde deve considerar alguns importantes pressupostos: a concepção de saúde como qualidade de vida; o contexto e a concepção de saúde, tendo os princípios da reforma sanitária como referência e o SUS como estratégia de reordenação setorial e institucional; os processos de trabalho em saúde, que guardam algumas especificidades (é coletivo e as decisões a serem tomadas implicam na articulação de vários saberes, que, por sua vez, provêm de várias instâncias: bases científicas e instrumentais, com ênfase no conhecimento científico, bases tecnológicas, com ênfase no conhecimento técnico, e a experiência de trabalho e social. Todas essas instâncias mediadas pela dimensão ético-política); a necessidade de desenvolver competências formais e ético-sociais que assegurem a competência necessária aos processos de trabalho em saúde.

Com estes pressupostos, a competência, na perspectiva dos processos de trabalho em saúde, incorpora múltiplas dimensões de 
saberes que, articulados, permitem que essa competência se integralize. Assim, a competência para os diversos processos de trabalho da saúde é complexa, multidimensional, global e integrativa.

Considerando os pressupostos e as características da competência profissional em saúde apresentados, fica evidente que a visão da competência apontada implica uma superação de práticas alienadas, marcadas muitas vezes pelo desconhecimento, pela imprecisão nas decisões, por formas de organização do trabalho não participativas, pela rotatividade de profissionais, pelas dificuldades de comunicação e de trabalho em equipe. E que, a superação de práticas alienadas efetiva-se pela construção de práticas em que a autonomia, o compromisso, a iniciativa e a responsabilidade sejam requisitos importantes na busca de soluções para os eventos com os quais os profissionais se deparam ${ }^{7}$. 0 desenvolvimento destes valores pelos profissionais favorece a superação de práticas descomprometidas com a realidade, referenciadas apenas em normas e rotinas previamente estabelecidas ${ }^{7}$.

Por isso mesmo, o desenvolvimento das práticas de saúde, dentre elas as da vigilância sanitária, deve pautar-se nas competências necessárias para a efetividade, segundo a lógica da qualidade das ações, da ética e do respeito aos direitos dos usuários dos serviços.

A partir dessas considerações, optou-se por adotar conceitos e proposições discutidos por Zarifian ${ }^{8}$ e Le Boterf ${ }^{9}$, uma vez que esses autores trazem uma visão ampliada da competência, sintonizada com a qualidade requerida pelo sistema de saúde brasileiro e com as necessidades de desenvolvimento de sua força de trabalho, apontando para a importância do trabalhador ser capaz de mobilizar conhecimentos, experiências e vivências, a fim de buscar soluções para os problemas que a realidade do trabalho apresenta (e resolvê-los!).

Zarifian $^{8}$ e Le Boterf ${ }^{9}$ compreendem a competência nas seguintes dimensões:

Competência é a tomada de iniciativa e o assumir de responsabilidade do indivíduo sobre problemas e eventos que ele enfrenta em situações profissionais ${ }^{8}$;

Competência é um saber agir com pertinência, saber mobilizar saberes e conhecimentos em um contexto profissional, saber integrar ou combinar saberes múltiplos e heterogêneos, saber transpor, saber aprender e aprender a aprender, saber envolver-se'.

Zarifian ${ }^{8}$ defende que a escolha, pelo trabalhador, dentre diferentes possibilidades ou caminhos a serem seguidos apoia-se em conhecimentos adquiridos e transformados a partir da diversidade das situações de trabalho vivenciadas. Então, para esse autor, a competência é balizada pela iniciativa e responsabilidade, pela capacidade de mobilizar redes de atores, de compartilhar desafios e de assumir áreas de responsabilidade. Ele afirma que a iniciativa é um componente fundamental para a autonomia, considerando que, para demonstrar iniciativa, o sujeito tem que agir frente a uma situação na sua vida profissional e iniciar alguma coisa para modificá-la, quando necessário.
Destaca-se que a abordagem da autonomia e da responsabilidade como atitudes sociais expressam novas opções de organização do trabalho e são construídas, basicamente, nas aprendizagens que geram comprometimentos na vida social e pessoal; é uma questão de "se tornar" autônomo e responsável ${ }^{10}$.

Finalmente, destaca-se que a opção pela visão de competência expressa pelos autores Zarifian ${ }^{8}$ e Le Boterf ${ }^{9}$ condiz com os princípios e pressupostos do sistema nacional de saúde e com as características das práticas da vigilância sanitária no Brasil, que requerem, dentre outras, iniciativa e antecipação aos problemas, interação e comunicação entre trabalhadores, gestores e usuários e trabalho interprofissional e em equipe, corroborando a ideia de que a mera qualificação técnica não mais responde às necessidades desses processos de trabalho.

Com essas considerações, os objetivos deste artigo foram apresentar a abordagem metodológica utilizada para elaborar o referencial de competências profissionais específicas para atuação em vigilância sanitária nas áreas de serviços de saúde, serviços de interesse para a saúde, inspeção e fiscalização (alimentos, medicamentos, cosméticos, saneantes e produtos para a saúde), inspeção e fiscalização de farmácias e drogarias, tabaco, sangue, tecidos, células e órgãos e apontar possibilidades de aplicação do material produzido.

\section{MÉTODO}

Trata-se de um estudo exploratório, com perspectiva qualitativa, que utilizou como suporte teórico a abordagem metodológica proposta por Zarifian ${ }^{8}$, conforme apresentado na Figura 1.

Essa metododologia também está descrita no capítulo intitulado "Construção de competências dos profissionais da atenção básica de saúde: proposta conceitual e metodológica”, do livro "Educação e trabalho: interface com a gestão em saúde”, no prelo $2020^{11}$.

Este método permitiu, no primeiro momento, uma contextualização das práticas da vigilância sanitária no Brasil, considerando as áreas de atuação definidas para o estudo. No segundo momento, o caminho metodológico percorrido possibilitou a recontextualização dessa prática na perspectiva de cumprir os objetivos das etapas definidas pela metodologia aplicada.

A sexta etapa não pôde ser realizada por motivos do contexto sanitário relacionado à pandemia do novo coronavírus em curso no país.

Fonte de dados empíricos

\section{Análise documental}

Documentos técnicos, leis, portarias e normas referentes à regulação das práticas da vigilância sanitária originários dos Ministérios da Saúde e da Agência Nacional de Vigilância Sanitária (Anvisa), no período entre 1990 e 2019; artigos, textos acadêmicos e cadernos de cursos, no período entre 2000 e 2018. Os dados foram analisados a partir de leitura exploratória e crítica dos documentos selecionados a fim de evidenciar informações, dados e conceitos específicos que permitissem alcançar os objetivos do estudo. 


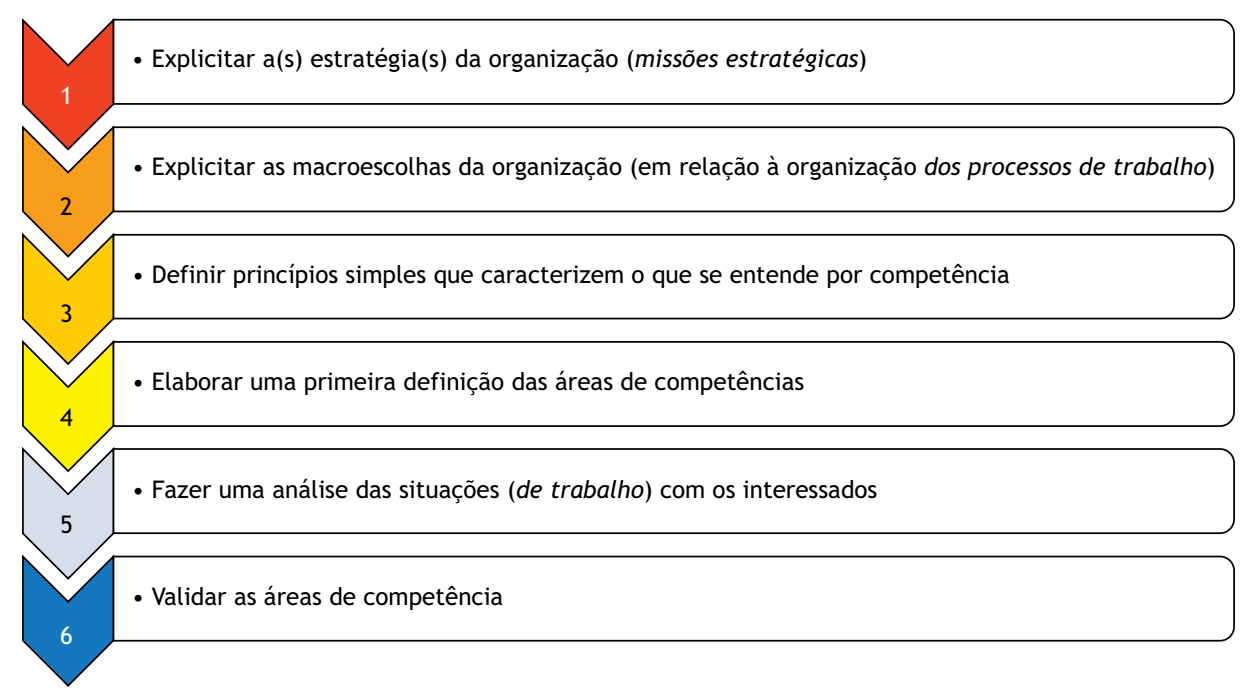

Fonte: Zarifian ${ }^{8}$.

Figura 1. Etapas do modelo de definição de competência proposto por Zarifian.

\section{Oficinas de trabalho}

Realizadas com trabalhadores oriundos de secretarias estaduais e municipais de saúde com experiência de atuação nas áreas da vigilância sanitária definidas para o estudo, sendo elas: serviços de saúde, serviços de interesse para a saúde, inspeção e fiscalização (alimentos, medicamentos, cosméticos, saneantes e produtos para a saúde), inspeção e fiscalização de farmácias e drogarias, tabaco, sangue, tecidos, células e órgãos.

Foi utilizada no estudo a metodologia intitulada "Mapeamento das competências profissionais específicas de trabalhadores da vigilância sanitária que atuam nas áreas: serviços de saúde, serviços de interesse para a saúde, inspeção e fiscalização (alimentos, medicamentos, cosméticos, saneantes, produtos para a saúde), inspeção e fiscalização de farmácias e drogarias, tabaco, sangue, tecidos, células e órgãos". 0 mapeamento dessas competências integra as ações do Programa Capacita-Visa que tem o propósito de apoiar a formação e a educação permanente voltadas ao desenvolvimento profissional de trabalhadores da Vigilância Sanitária, consoante à natureza, complexidade e missão da vigilância sanitária no Brasil.

A opção por essa metodologia pedagógica considerou seus principais objetivos que são: a construção coletiva de um saber, a análise da realidade, a confrontação e o intercâmbio de experiências ${ }^{12}$.

Esse tipo de abordagem propicia aos participantes a oportunidade de vivenciar situações concretas e significativas, baseadas no tripé sentir-pensar-agir, atendendo, basicamente, a duas finalidades: (a) articulação de conceitos, pressupostos e noções com ações concretas, vivenciadas pelo trabalhador; b) vivência e execução de tarefas em equipe, isto é, apropriação ou construção coletiva de saberes, obtendo-se com esse processo a apropriação, a construção e a produção de conhecimentos teóricos e práticos de forma ativa e reflexiva ${ }^{13}$.
A estratégia pedagógica vivenciada nas oficinas foi a problematização das práticas com sucessivas aproximações ao objeto central das discussões: a análise dos processos de trabalho da vigilância sanitária, na perspectiva dos próprios trabalhadores. Significa dizer que as atividades da oficina foram organizadas de forma sequenciada, buscando uma reflexão sobre as práticas que permitisse, nos limites propostos pelos objetivos da oficina, aprofundar, acrescentar e sistematizar, coletivamente, o conteúdo das discussões. Com isso, buscou-se a problematização da realidade (das práticas) e a facilitação do processo de abstração vinculado à totalidade, seguindo a metodologia, com adaptações, do documento original "Capacitação pedagógica para instrutores/supervisores: área da saúde"14. As discussões sobre as práticas foram realizadas por meio de atividades de socialização, em que cada um relatou suas ações efetivas, compartilhando-as com os colegas, interrogando-os e, a partir disso, refletindo sobre os meios - processuais e técnicos - de colocá-las em prática (ou seja, o saber-agir; as ações que realizam no cotidiano - ou não - do trabalho).

As oficinas tiveram participação de profissionais de 26 estados, apenas os participantes do Distrito Federal não participaram do processo das oficinas, e de 25 municípios, com faixas populacionais entre 10.000 a 500.000 habitantes.

Para a participação de representantes municipais foi realizada uma seleção dos municípios baseada em cinco faixas populacionais, conforme descrito abaixo:

- Municípios <= 10.000 habitantes (ha)

- Municípios de $10.001 \mathrm{a}<=20.000$ habitantes (ha)

- Municípios de $20.001 \mathrm{a}<=50.000$ habitantes (ha)

- Municípios de $50.001 \mathrm{a}>=500.000$ habitantes (ha)

- Municípios acima de 500.000 habitantes (ha) 
Cada município selecionado indicou um profissional atuante na área de vigilância sanitária para participar, o qual foi distribuído em uma das oficinas, conforme a região do país onde o município está localizado.

Para caracterizar o perfil dos participantes das oficinas, foi utilizado o método de elaboração individual de narrativa sobre a trajetória profissional em vigilância sanitária. Essa elaboração foi orientada por um roteiro balizador organizado em duas partes: a primeira compreendeu o levantamento de informações sobre data de nascimento, sexo, formação acadêmica, tempo de atuação na vigilância sanitária, estado e cidade onde atua e área(s) de atuação na vigilância sanitária. A segunda parte solicitou a opinião dos profissionais sobre: saberes sociais importantes para atuação em vigilância sanitária; condições que facilitam o trabalho; condições que dificultam o trabalho; condições do trabalho em equipe; autonomia para a execução do trabalho; e repercussão social do trabalho.

O relato detalhado de todas as etapas do estudo, realizado entre 2019 e 2020, está descrito no formato de relatórios técnicos disponibilizados junto à Anvisa, que mantém os arquivos em seu sistema eletrônico interno.

\section{RESULTADOS E DISCUSSÃO}

A análise documental realizada identificou a vigilância sanitária como um campo singular da saúde pública, que envolve articulações de natureza econômica, jurídico-política e médico-sanitária. É uma prática social e histórica estruturada pelo Estado para a defesa e a proteção da saúde. Seu trabalho incide sobre as especificidades de seus objetos de controle, que devem ser abordados a partir dos atributos de qualidade requeridos desses objetos, presentes no mercado como mercadoria e, ao mesmo tempo, como bens sociais de interesse da saúde pública ${ }^{15}$.

Os documentos selecionados permitiram compreender a natureza, as dimensões e o alcance social da vigilância sanitária, a complexidade da sua ação, as características da força de trabalho que atua na área e o conjunto organizado das práticas que caracterizam o trabalho da vigilância sanitária, considerando suas dimensões tecnológica, sistêmica, intersetorial, ética e de abrangência social.

O Quadro 1 apresenta a relação dos documentos analisados, sua origem e ano de publicação.

Os conteúdos organizados a partir desses documentos foram sistematizados com o propósito de cumprir as etapas do modelo da competência desenvolvido por Zarifian. A seguir, cada etapa da metodologia é apresentada considerando seus principais aspectos, resultados e discussão.

Uma reflexão importante quando se trata de apresentar saberes que apoiam o desenvolvimento de competências, diz respeito à aceitação de que as condições para a sua formação se apresentam em uma multiplicidade de lugares de socialização, entre os quais: a formação acadêmica, a educação permanente e a educação continuada?.

Considerando esta observação de Zarifian, outro importante destaque é que o Ministério da Saúde definiu uma política de educação permanente em saúde (EPS) que se configura como aprendizagem no trabalho, em que o aprender e o ensinar se incorporam ao cotidiano das organizações e ao trabalho, no contexto real em que ocorrem ${ }^{27}$. A EPS considera a prática como fonte de conhecimentos e de problemas, problematizando o próprio fazer; coloca os trabalhadores como atores reflexivos da prática e construtores do conhecimento e de alternativas de ação.

Estes dois destaques demonstram que a forma de conceber e praticar a educação permanente, conforme a política definida pelo Ministério da Saúde, tem grande afinidade com a perspectiva de Zarifian $^{8}$, quando ele afirma que a formação das competências se dá de múltiplas formas e em múltiplos lugares, resgatando, assim, dentre outras, o papel formativo do trabalho e a importância da troca e análises de experiências na formação profissional.

Quadro 1. Documentos analisados, instituição de origem/autores e ano de publicação. Brasil, 1990-2019.

\begin{tabular}{|c|c|c|}
\hline Documento & Instituição de origem/autores & Ano da publicação \\
\hline Lei Federal $n^{\circ} 8.080$ de 19 de setembro & Brasil $^{16}$ & 1990 \\
\hline Lei Federal $n^{\circ} 9.782$ de 26 de janeiro & Brasil $^{17}$ & 1999 \\
\hline Artigo: Constituição da vigilância sanitária no Brasil & Costa e Rozenfeld ${ }^{18}$ & 2000 \\
\hline Portaria GM/MS n 1.052 & Ministério da Saúde ${ }^{19}$ & 2007 \\
\hline Artigo: Trabalho em vigilância sanitária: conceitos teóricos para a reflexão sobre as práticas & Souza e Costa ${ }^{20}$ & 2009 \\
\hline Artigo: Conceitos e área de abrangência, em fundamentos da vigilância sanitária & Costa $^{21}$ & 2009 \\
\hline $\begin{array}{l}\text { Artigo: Considerações teóricas e conceituais acerca do trabalho em vigilância sanitária, campo } \\
\text { específico do trabalho em saúde }\end{array}$ & Souza e Costa ${ }^{15}$ & 2010 \\
\hline Perfil dos estados e dos municípios brasileiros: 2014/IBGE & Brasil $^{22}$ & 2015 \\
\hline $\begin{array}{l}\text { Ciclo de Debates em Vigilância Sanitária: desafios e tendências. De qual vigilância sanitária a } \\
\text { sociedade precisa? }\end{array}$ & Anvisa $^{23}$ & 2015 \\
\hline $\begin{array}{l}\text { Projeto de Apoio ao Sistema Único de Saúde: Gestão da Vigilância Sanitária } \\
\text { Curso: Especialização em Gestão da Vigilância Sanitária. Caderno do curso } 2017\end{array}$ & Ramos et al. ${ }^{24}$ & 2017 \\
\hline Artigo: SUS 30 anos: Vigilância Sanitária & Silva, Costa e Lucchese ${ }^{25}$ & 2018 \\
\hline Compilado de procedimentos do Sistema Nacional de Vigilância Sanitária & Anvisa ${ }^{26}$ & $\begin{array}{l}2019 \text { - Última } \\
\text { atualização }\end{array}$ \\
\hline
\end{tabular}

Fonte: Elaborado pelas autoras, 2020. 
Primeira etapa: explicitando as estratégias de vigilância sanitária no Brasil

Segundo Zarifian ${ }^{8}$, explicitar as estratégias da instituição é o ponto de partida para construir o referencial de competências necessário a seus trabalhadores, pois são elas que determinam a orientação a ser dada às competências. 0 autor salienta que não se trata de explicitar todos os detalhes dessas estratégias, mas de expressá-las, sinteticamente, no que elas têm de essencial. A partir das análises realizadas, foi possível expressar três estratégias, formalizadas como "missões estratégicas", apresentadas no Quadro 2.

Uma importante característica dessas missões estratégicas é que elas sejam relativamente duráveis, não variando conforme as conjunturas e não sendo dependentes de um ou outro instrumento de medida ${ }^{8}$.

Deve-se salientar que a identificação das áreas de competência é focada nessas missões estratégicas a fim de manter-se a coerência da abordagem metodológica.

Para tanto, a pergunta feita durante todo o processo é: a que missão estratégica deve ser vinculada tal ou qual competência?'.

Segunda etapa: explicitando as macroescolhas da vigilância sanitária no Brasil

Depois de definidas as estratégias, foram expressadas as escoIhas da vigilância sanitária em relação à forma de organização do trabalho. No entanto, pela lógica proposta por Zarifian ${ }^{8}$, não foi necessário precisar detalhadamente essas escolhas (por isso, se utilizou a expressão macroescolhas). Tampouco elas são consideradas definitivas, pois a experiência e a evolução das políticas e dos processos aos quais elas estejam referidas poderão mostrar outras alternativas.

É importante explicitar essas escolhas "porque elas configuram de antemão os espaços e as temporalidades de exercício das competências"'.

Em relação a essa etapa, foram identificadas três possíveis macroescolhas para a organização do trabalho na área da vigilância sanitária mostradas no Quadro 3.
Terceira etapa: definindo princípios simples que caracterizam a visão da competência profissional pela vigilância sanitária no Brasil

Essa etapa estabelece, de certa forma, uma "filosofia" da competência. Tais princípios foram encontrados, de forma bem explícita e atual, no documento "Compilado de procedimentos do Sistema Nacional de Vigilância Sanitária - 30/08/2019 (Revisão 014 - GGFIS)"26. Ali, foi apresentado um conjunto amplo de atributos considerados fundamentais ao profissional da vigilância sanitária. Destacam-se:

- A ética;

- 0 trabalho em equipe e prática colaborativa;

- A capacidade de adaptar-se a diferentes situações;

- A comunicação;

- A capacidade de observação e análise da realidade de diferentes contextos sociais.

Quarta etapa: elaborando uma primeira definição das áreas de competência

Essa etapa é a expressão direta das três primeiras. A pergunta respondida, nesse momento, é: em função das missões estratégicas, das macroescolhas da instituição e dos princípios que caracterizam a visão da competência profissional, como, em uma primeira abordagem, desenhar as grandes áreas de competência?8.

É importante ressaltar que as áreas de competência propostas nessa etapa ainda não são delimitadas enquanto áreas específicas de atuação profissional em vigilância sanitária. Elas são genéricas, provêm de uma visão de conjunto. Nesse sentido, optou-se por adotar a divisão das áreas de competências, conforme propôs Deluiz²:

- Técnicas: domínio dos conteúdos das ações, das regras e dos procedimentos da área de trabalho; compreensão dos processos e do manejo de equipamentos; compreensão dos sistemas e das redes de relações e das formas de obter e usar as informações.

Quadro 2. Estratégias de vigilância sanitária definidas a partir da análise documental realizada dos documentos mencionados no Quadro 1.

Missões estratégicas de vigilância sanitária
Defender o interesse público da saúde por meio de um conjunto de práticas que visam a proteção individual e coletiva da saúde
Adotar os princípios da intercomplementaridade e da interdependência dos processos e dos meios de trabalho
Assentar-se no trabalho em equipe e na multiprofissionalidade

Fonte: Elaborado pelas autoras, 2020.

Quadro 3. Macroescolhas para a organização do trabalho na área da vigilância sanitária explicitadas a partir do estudo realizado.

Modelo de organização coletiva do trabalho, que requer distintas tecnologias de intervenção, saberes especializados e valores ético-políticos bem definidos.
Modelo de regulação sanitária das atividades relacionadas ao ciclo produção/consumo.
Definição de instrumentos ou meios de trabalho utilizados para a realização do controle sanitário.

Definição de instrumente: Elaborado pelas autoras, 2020. 
- Organizacionais: autoplanejamento e auto-organização; estabelecimento de métodos próprios, gerenciamento do tempo e do espaço de trabalho; desenvolvimento da flexibilidade e da criatividade no processo de trabalho; utilização dos conhecimentos - obtidos através de fontes, meios e recursos diferenciados - nas diversas situações encontradas no mundo do trabalho; transferência de conhecimentos da vida cotidiana para as situações de trabalho e vice-versa.

- Comunicativas: expressão e comunicação com seu grupo, superiores hierárquicos ou subordinados e com os usuários; cooperação; trabalho em equipe; prática do diálogo; exercício da negociação; comunicação interpessoal.

- Sociopolíticas: reflexão sobre a esfera do mundo do trabaIho; consciência da qualidade e das implicações éticas do seu trabalho; autonomia de ação; compromisso social; desenvolvimento do exercício da cidadania; abertura para mudanças; desenvolvimento da autoestima e da autovalorização.

Quinta etapa: fazendo uma análise das situações com os interessados - os próprios trabalhadores

Realizada por meio das oficinas de trabalho. Foram organizados grupos mistos, compostos por trabalhadores com diferentes trajetórias em termos de formação, experiência e vínculos de trabalho, de áreas que compõem a vigilância sanitária, conforme definição feita para o estudo. 0 objetivo dessa composição de grupo foi alcançar as especificidades e possiveis transversalidades do trabalho, considerando também suas diversidades em relação aos locais de produção dos serviços para o atendimento das demandas institucionais e sociais.

Todos os participantes das oficinas eram vinculados aos departamentos de vigilância sanitária de secretarias estaduais ou municipais de saúde, atuantes em pelo menos uma das áreas mencionadas, por um tempo mínimo de um ano.

Foram realizadas cinco oficinas, conforme sistematizado no Quadro 4, com o objetivo de discutir os processos de trabalho vivenciados pelos trabalhadores e elaborar, a partir de suas experiências e práticas, um quadro de ações específicas, na perspectiva de apoiar a identificação das competências que precisam ser desenvolvidas e mobilizadas como condição para o alcance dos objetivos estratégicos da vigilância sanitária.

O Quadro 5 apresenta a distribuição dos participantes por região, estados e municípios, sexo, faixa etária e esfera de vinculação ao departamento de vigilância sanitária (estadual ou municipal).

As oficinas de trabalho possibilitaram a elaboração coletiva de um quadro das ações realizadas no cotidiano (ou não) do trabalho.

As Figuras 2 e 3 ilustram o levantamento e a classificação das ações realizados pelos profissionais participantes de uma das oficinas.

Quadro 4. Distribuição dos participantes das oficinas por região, quantidade de oficinas, datas de realização e número de participantes.

\begin{tabular}{|lccc|}
\hline Região & Número de oficinas & Datas & Número de participantes \\
\hline Nordeste & 2 & $15 / 10 / 2019$ e $17 / 10 / 2019$ & 16 \\
Norte & 1 & $22 / 10 / 2019$ & 13 \\
Centro-Oeste & 1 & $24 / 10 / 2019$ & 8 \\
Sul e Sudeste & 1 & $05 / 11 / 2019$ & 15 \\
\hline Total geral & 5 & - & 52 \\
\hline
\end{tabular}

Fonte: Elaborado pelas autoras, 2020.

Quadro 5. Distribuição dos participantes por região, estados e municípios, sexo, faixa etária e esfera de vinculação ao departamento de vigilância sanitária (estadual ou municipal).

\begin{tabular}{|c|c|c|c|c|c|c|}
\hline Região & Estados/Municípios & $\begin{array}{c}\text { Total } \\
\text { participantes }\end{array}$ & Sexo & Faixa etária & $\begin{array}{c}\text { Visa } \\
\text { estadual }\end{array}$ & $\begin{array}{c}\text { Visa } \\
\text { municipal }\end{array}$ \\
\hline Centro-Oeste & $\begin{array}{c}\text { GO, MS, MT } \\
\text { Goiânia, Campo Verde, Aquidauana, Terenos, Corumbá }\end{array}$ & 8 & $\begin{array}{l}\text { Fem }>5 \\
\text { Masc }>3\end{array}$ & $\begin{array}{c}\text { Fem: } 31 \text { a } 50 \text { anos }>\text { todas } \\
\text { Masc: } 31 \text { a } 50>2 \\
\text { Acima de } 50>1\end{array}$ & 3 & 5 \\
\hline Nordeste & $\begin{array}{c}\text { AL, BA, CE, MA, PB, PE, PI, RN, SE } \\
\text { São Luís do Curu, Campo Grande, Arapiraca, Natal, } \\
\text { Água Branca, Recife, Feira de Santana e Caruaru }\end{array}$ & 16 & $\begin{array}{l}\text { Fem }>11 \\
\text { Masc }>5\end{array}$ & $\begin{array}{c}\text { Fem: } 31 \text { a } 50 \text { anos }>6 \\
\text { Acima de } 50 \text { anos }>5 \\
\text { Masc: } 31 \text { a } 50>1 \\
\text { Acima de } 50>4\end{array}$ & 8 & 8 \\
\hline Norte & $\begin{array}{c}\text { AC, AM, AP, PA, RO, RR, TO } \\
\text { Rio Branco, Macapá, Castanhal, Mucajaí, Porto Nacional }\end{array}$ & 13 & $\begin{array}{l}\text { Fem }>6 \\
\text { Masc }>7\end{array}$ & $\begin{array}{l}\text { Fem: } 31 \text { a } 50 \text { anos }>4 \\
\text { Acima de } 50 \text { anos }>2 \\
\text { Masc: } 31 \text { a } 50>3 \\
\text { Acima de } 50>4\end{array}$ & 6 & 7 \\
\hline Sudeste e Sul & $\begin{array}{c}\text { ES, MG, RJ, SP, PR, RS, SC } \\
\text { Diadema, Betim, Tijucas, Rio Acima, Vila Velha, } \\
\text { Gramado, Pinhais }\end{array}$ & 15 & $\begin{array}{l}\text { Fem }>12 \\
\text { Masc }>3\end{array}$ & $\begin{array}{c}\text { Fem: } 31 \text { a } 50 \text { anos }>9 \\
\text { Acima de } 50 \text { anos }>3 \\
\text { Masc: } 31 \text { a } 50>3 \\
\text { Acima de } 50>0\end{array}$ & 8 & 7 \\
\hline Totais & $\begin{array}{c}\text { Estados }>26 \\
\text { Municípios }>25\end{array}$ & 52 & $\begin{array}{l}\text { Fem }>34 \\
\text { Mas }>18\end{array}$ & $\begin{array}{c}\text { Fem: } 31 \text { a } 50>24 \\
\text { Fem: acima } 50>10 \\
\text { Masc: } 31 \text { a } 50>9 \\
\text { Masc: acima de } 50>9\end{array}$ & 25 & 27 \\
\hline
\end{tabular}

GO: Goiás; MS: Mato Grosso do Sul; MT: Mato Grosso; AL: Alagoas: BA: Bahia; CE: Ceará; MA: Maranhão; PB: Paraíba; PE: Pernambuco; PI: Piauí; RN: Rio Grande do Norte; SE: Sergipe; AC: Acre; AM: Amazonas; AP: Amapá; PA: Pará; RO: Rondônia; RR: Roraima; TO: Tocantins; ES: Espirito Santo; MG: Minas Gerais; RJ: Rio de Janeiro; SP: São Paulo; PR: Paraná; RS: Rio Grande do Sul; SC: Santa Catarina; Fem: feminino; Masc: masculino; Visa: Vigilância Sanitária. Fonte: Elaborado pelas autoras, 2020. 


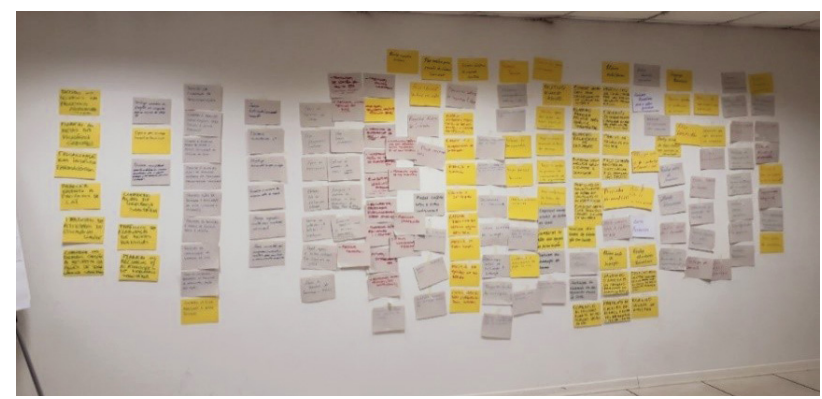

Fonte: Elaborada pelos autores, 2020.

Figura 2. Foto do levantamento das ações realizadas pelos profissionais participantes de uma das oficinas.

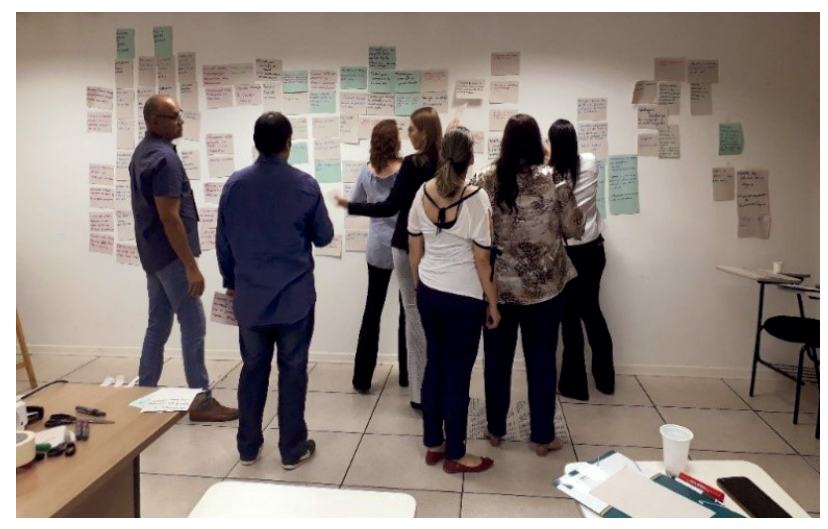

Fonte: Elaborada pelos autores, 2020.

Figura 3. Foto da classificação das ações, realizada pelos profissionais participantes de uma das oficinas.

Os grupos classificaram as ações levantadas segundo critérios que retomaram a definição de vigilância sanitária contida na Lei $\mathrm{n}^{\circ} 8.080 / 1990^{16}$ como um

conjunto de ações capaz de eliminar, diminuir ou prevenir riscos à saúde e de intervir nos problemas sanitários decorrentes do meio ambiente, da produção e circulação de bens e da prestação de serviços de interesse da saúde, abrangendo (i) o controle de bens de consumo que, direta ou indiretamente, se relacionem com a saúde, compreendidas todas as etapas e processos, da produção ao consumo; e (ii) o controle da prestação de serviços que se relacionam direta ou indiretamente com a saúde.

Pertinente a essa definição, a seguinte classificação das ações foi proposta pelos participantes:

- Promoção da saúde, prevenção de riscos sanitários;

- Educação permanente e continuada;

- Planejamento e gestão;

- Monitoramento da qualidade de produtos e serviços;

- Atuação como polícia administrativa.
A partir dos resultados obtidos nas oficinas, uma nova sistematização foi realizada, no sentido de conformar um referencial de competências que também incorporasse os resultados obtidos nas etapas anteriores da metodologia: as missões estratégicas da vigilância sanitária, suas macroescolhas, áreas de competências e valores e princípios levantados como transversais às competências.

Como resultado final de todo o processo metodológico percorrido, foram elaboradas sete competências específicas para atuação nas áreas da vigilância sanitária definidas para o estudo (serviços de saúde, serviços de interesse para a saúde, inspeção e fiscalização (alimentos, medicamentos, cosméticos, saneantes e produtos para a saúde), inspeção e fiscalização de farmácias e drogarias, tabaco, sangue, tecidos, células e órgãos), que compõem o referencial de competências apresentado na Figura 4.

Para cada competência, foi explicitado o conjunto das ações que a compõe e que devem ser desenvolvidas pelos profissionais para seu alcance. Ainda como parte desse referencial, são apontados os saberes que precisam ser articulados e mobilizados para a realização das várias ações vinculadas às competências.

No referencial de competências elaborado, optou-se pela apresentação conjunta dos saberes, ou seja, não discriminados em relação a cada uma das competências. São considerados em suas múltiplas dimensões, tal como descreve Deluiz ${ }^{2}$ : saberes cognitivos: conhecimentos, saber-saber e saber fazer cognitivos; saberes operacionais: técnicos, saber-fazer, práticas, processos; saberes reflexivos: compreendidos como comportamentos e atitudes de reflexão, de questionamento; saberes psicoativos: conhecimento de si, gestão do estresse, capacidade de investimento pessoal; e saberes psicossociais: saberes relacionais, capacidade de comunicar-se.

\section{Sexta etapa: organizando o processo de validação}

A validação da proposta do referencial de competências objetiva divulgar o material produzido, possibilitar a participação de atores interessados no assunto, buscar consenso em torno das competências profissionais e buscar subsídios para o aperfeiçoamento da proposta. Essa etapa será realizada em momento oportuno, em que o processo de validação poderá ser realizado online, mediante a elaboração de formulários eletrônicos que permitam um tratamento estatístico às sugestões recebidas. Os relatórios gerados serão utilizados para análise final pela equipe organizada para esse fim.

A Figura 5 ilustra um possível formato de formulário eletrônico que poderá ser utilizado para a coleta de informações na etapa de validação.

Estima-se um prazo de 30 dias corridos para a efetivação da validação e o público-alvo do processo sugerido deverá ser constituído por profissionais dos serviços que atuam diretamente nas ações de vigilância sanitária; órgãos gestores (Anvisa, Ministério da Saúde e da Educação, secretarias estaduais e municipais de saúde, coordenações estaduais de vigilância sanitária, prefeituras e outros); o Conselho Nacional de Saúde (CNS); o Conselho Nacional de Secretários de Saúde (CONASS); a Câmara Técnica de Recursos Humanos do CONASS; o Conselho Nacional de Secretários Municipais de Saúde (CONASEMS); conselhos municipais de saúde; fundações; e pessoas físicas. 
REFERENCIAL DE COMPETÊNCIAS ESPECÍFICAS PARA ATUAÇÃO EM VIGILÂNCIA SANITÁRIA

Desenvolver ações que reflitam a compreensão do processo saúde-doença e a apreensão dos conceitos e estratégias da promoção da saúde da população e do controle social das práticas da vigilância sanitária.

Atuar na transformação de práticas sanitárias geradoras de prejuízos à sociedade, por meio da aplicação de instrumentos legais de controle dos riscos e de correção dessas práticas, considerando, ainda, o papel educativo desse processo.
Implementar ações de prevenção e controle de riscos sanitários dirigidas à população, grupos específicos e setor regulado, considerando necessidades de informação e orientação, bem como características dos espaços e contextos onde o trabalho é realizado. processo de trabalho em vigilância sanitária, utilizando conceitos e ferramentas do planejamento e dos sistemas de informação.

Implementar estratégias e tecnologias da vigilância sanitária voltadas ao monitoramento da qualidade de produtos e serviços de interesse da saúde, incluindo locais e técnicas de produção, circulação e comercialização desses produtos e serviços.
Implementar processos sistematizados de educação para o trabalho, incluindo educação permanente, pesquisas e práticas relacionadas ao aperfeiçoamento em vigilância sanitária.

Desenvolver capacidade crítica, de reflexão e de mudança ativa de suas práticas; de trabalhar em equipe e de aperfeiçoar a comunicação entre seus pares e outros grupos sociais, pautando suas ações nos princípios da ética e da responsabilidade profissional.

Fonte: Elaborada pelas autoras, 2020.

Figura 4. Competências específicas para atuação nas áreas da vigilância sanitária definidas para o presente estudo, que compõem o referencial de competências.

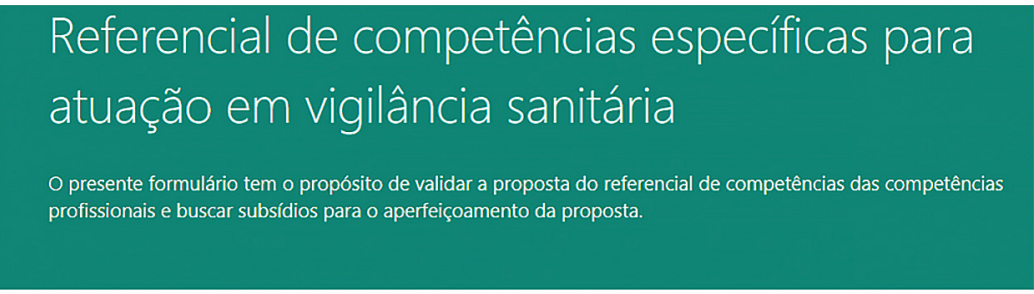

Olá Claudia, quando enviar este formulário, o seu nome e endereço de email serăo exibidos para o proprietário do formulário.

1. Considerando a competência abaixo, selecione para cada ação, uma das opções apresentadas:

(1) Atuar na transformação de práticas sanitárias geradoras de prejuízos à sociedade, por meio da aplicação de ferramentas legais de controle dos riscos e de correção dessas práticas, considerando o papel educativo desse processo.

AÇÃO 1: Realizar inspeções sanitárias sistemáticas e investigativas.

Faço

Não faço

Faço, mas não deveria fazer

Não faço, mas deveria fazer

Fonte: Elaborada pelas autoras, 2020.

Figura 5. Possível formato de formulário eletrônico que poderá ser utilizado para a coleta de informações na etapa de validação para conclusão da etapa 6.

Ainda é preciso destacar que a última etapa da metodologia aplicada nesse estudo não pôde ser realizada, conforme explicitado anteriormente. No entanto, a validação é considerada um requisito indispensável para a obtenção de informações sobre a viabilidade e coerência política, técnica e pedagógica da proposta, considerando a missão, os objetivos, as estratégias e a natureza das práticas da vigilância sanitária no Brasil. Além disso, a validação apontará tendências de transformação do escopo da 
prática dos trabalhadores que atuam nas áreas analisadas pelo estudo, bem como seu potencial enquanto ferramenta de gestão da educação e do trabalho em vigilância sanitária.

É importante destacar que as proposições feitas em cada etapa, a partir das análises realizadas, foram debatidas e acordadas com a equipe da Anvisa que coordenou a realização do estudo.

\section{CONCLUSÕES}

O caminho metodológico percorrido, com destaque para os processos vivenciados nas oficinas, possibilitou maior visibilidade das práticas desenvolvidas pelos profissionais da vigilância sanitária. As discussões realizadas corroboraram as ideias e proposições desenvolvidas em todas as etapas anteriores da metodologia, na medida em que os depoimentos e as análises realizadas entre os participantes deram voz ao que havia sido analisado acerca da natureza, das dimensões e do alcance social da vigilância sanitária, da complexidade da sua ação, das características da força de trabalho que atua na área e de seu escopo de prática.

Por outro lado, as análises que possibilitaram a aplicação das quatro primeiras etapas da metodologia nortearam o trabalho nas oficinas, no sentido de conformar um referencial de competências sintonizado com a missão da vigilância sanitária, suas estratégias e macroescolhas e os valores e os princípios levantados como transversais às competências. É importante destacar que os processos de discussão e análise evidenciaram um perfil de competências amplo, que abrangeu todas as áreas de atuação estudadas.

Foi possível visualizar o escopo da prática em uma perspectiva articulada aos princípios da saúde pública. A sistematização final das ações e dos saberes considerou os resultados obtidos em cada oficina, gerando consolidados representativos de todas as discussões realizadas com o conjunto dos 52 profissionais participantes.

Finalmente, ressaltam-se dois aspectos: (i) os resultados alcançados com este estudo e que permitiram elaborar a proposta do referencial de competências apresentado apontam que as competências descritas se alinham àquelas encontradas em ação desenvolvida dentro do Projeto de Apoio ao Sistema Único de Saúde (PROADI-SUS) ${ }^{24}$ para definir o perfil de competência do gestor da vigilância sanitária e organizar o curso de especialização em gestão da vigilância sanitária em 2017; (ii) a proposta do referencial de competências elaborado, após validada, subsidiará a organização de programas de educação permanente e de educação continuada para trabalhadores da vigilância sanitária e a construção de metodologias e instrumentos de avaliação de competências, contribuindo com a gestão da educação e dos processos de organização do trabalho nessa área.

Esses dois aspectos evidenciam a necessidade de investir em uma formação que permita refletir e buscar o desenvolvimento de competências para as várias áreas de atuação da vigilância sanitária no Brasil.

\section{REFERÊNCIAS}

1. Organização Internacional do Trabalho - OIT. Certificação de competências profissionais análise qualitativa do trabalho: avaliação e certificação de competências: referenciais metodológicos. Brasília: Organização Internacional do Trabalho; 2002.

2. Deluiz N. O modelo das competências profissionais no mundo do trabalho e na educação: implicações para o currículo. Bol Tec Senac. 2001;27(1):12-25.

3. Deluiz N. Qualificação, competências e certificação: visão do mundo do trabalho. In: Ministério da Saúde (BR). Formação: humanizar cuidados de saúde: uma questão de competência. Brasília: Ministério da Saúde; 2001. p. 5-15.

4. Brasil. Lei N. ${ }^{\circ}$ 9.394, de 20 de dezembro de 1996. Estabelece as diretrizes e bases da educação nacional. Diário Oficial União. 26 dez 1996.

5. Ramos MN. A pedagogia das competências: autonomia ou adaptação? São Paulo: Cortez; 2001.

6. Ministério da Saúde (BR). Referências conceituais para a organização do sistema de certificação de competências. Brasília: Ministério da Saúde; 2000.

7. Marques CMS. As competências crítico-emancipatórias e a formação dos trabalhadores de nível médio em enfermagem [dissertação]. São Paulo: Universidade de São Paulo; 2007.
8. Zarifian P. O modelo da competência: trajetória histórica, desafios atuais e propostas. São Paulo: Serviço Nacional de Aprendizagem Comercial; 2003.

9. Le Boterf G. Desenvolvendo a competência dos profissionais. Porto Alegre: Artmed; 2003.

10. Zarifian P. Objetivo competência: por uma nova lógica. São Paulo: Atlas; 2001.

11. Marques CMS, Haddad E, Peduzzi M, Leonello VM, Silva JAM, Anselmi ML et al. Construção de competências dos profissionais da atenção básica de saúde: proposta conceitual e metodológica. In: Castro JL, Vilar RL, Dias MA. Educação e trabalho: interface com a gestão em saúde. No prelo 2020

12. Gomes AR, Santos ACB, Vilarim C, Gomes CR, Gomes MR. O que é oficina pedagógica. Blog César Brito. 19 ago 2008.

13. Paviani NMS, Fontana NM. Oficinas pedagógicas: relato de uma experiência. Filos Educ. 2009;14(2):77-88.

14. Ministério da Saúde (BR). Capacitação pedagógica para instrutores/supervisores: área da saúde. Brasília: Ministério da Saúde; 1989.

15. Souza GS, Costa EA. Considerações teóricas e conceituais acerca do trabalho em vigilância sanitária, campo específico do trabalho em saúde. Cienc Saude Coletiva. 2010;15(Supl.3):3329-40. https://doi.org/10.1590/S1413-81232010000900008 
16. Brasil. Lei N. ${ }^{\circ} 8.080$, de 19 de setembro de 1990. Dispõe sobre as condições para a promoção, proteção e recuperação da saúde, a organização e o funcionamento dos serviços correspondentes e dá outras providências. Diário Oficial União. 20 set 1990.

17. Brasil. Lei N. ${ }^{\circ} 9.782$, de 26 de janeiro de 1999. Define 0 Sistema Nacional de Vigilância Sanitária, cria a Agência Nacional de Vigilância Sanitária, e dá outras providências. Diário Oficial União. 27 jan 1999.

18. Costa EA, Rozenfeld S. Constituição da vigilância sanitária no Brasil. Rio de Janeiro: Fundação Oswaldo Cruz; 2000.

19. Ministério da Saúde (BR). Portaria N. ${ }^{\circ} 1.052$, de 8 de maio de 2007. Aprova e divulga o plano diretor de vigilância sanitária. Diário Oficial União. 30 maio 2007.

20. Souza GS, Costa EA. Trabalho em vigilância sanitária: conceitos teóricos para a reflexão sobre as práticas. Salvador: Universidade Federal da Bahia; 2009.

21. Costa EA. Conceitos e área de abrangência. In: Rozenfeld S, organizadora. Fundamentos da vigilância sanitária. Rio de Janeiro: Fundação Oswaldo Cruz; 2009. p. 41-8
22. Instituto Brasileiro de Geografia e Estatística - IBGE. Perfil dos estados e dos municípios brasileiros: 2014. Rio de Janeiro: Instituto Brasileiro de Geografia e Estatística; 2015.

23. Agência Nacional de Vigilância Sanitária - Anvisa. Relatório do fórum nacional: ciclo de debates: desafios e tendências. Brasília: Agência Nacional de Vigilância Sanitária; 2015.

24. Ramos L, Petta HL, Massaro A, Lima VV, Araújo DG, Brito MM et al. Nota técnica: perfil de competência do especialista em gestão da vigilância sanitária. São Paulo: Instituto Sírio-Libanês de Ensino e Pesquisa; 2017.

25. Silva JAA, Costa EA, Lucchese G. SUS 30 anos: vigilância sanitária. Cienc Saude Coletiva. 2018;23(6):1953-61. https://doi.org/10.1590/1413-81232018236.04972018

26. Agência Nacional de Vigilância Sanitária - Anvisa. Compilado de procedimentos do Sistema Nacional de Vigilância Sanitária. Brasília: Agência Nacional de Vigilância Sanitária; 2019.

27. Ministério da Saúde (BR). Política nacional de educação permanente em saúde: o que se tem produzido para seu fortalecimento? Brasília: Ministério da Saúde; 2018.

\section{Agradecimentos}

Equipe gestora e técnica da Anvisa: Claudia Passos Guimarães Rabelo, Fernanda Horne da Cruz, Janaína Lopes Domingos, Lílian Fernandes da Cunha, Mariângela Torchia do Nascimento e Rosaura Maria da Costa Hexsel.

\section{Contribuição dos Autores}

Marques CMS - Concepção, planejamento (desenho do estudo), aquisição, interpretação dos dados e redação do trabalho. Rabelo CPG - Redação do trabalho. Todos os autores aprovaram a versão final do trabalho.

Conflito de Interesse

Os autores informam não haver qualquer potencial conflito de interesse com pares e instituições, políticos ou financeiros deste estudo.

Esta publicação está sob a licença Creative Commons Atribuição 3.0 não Adaptada.

Para ver uma cópia desta licença, visite http://creativecommons.org/licenses/by/3.0/deed.pt_BR. 